\title{
Cytogenetic and molecular genotyping in the allotetraploid Festuca pratensis $\times$ Lolium perenne hybrids
}

\author{
Joanna Majka ${ }^{1 *}$ D, Katarzyna Bzdęga ${ }^{2}$, Agnieszka Janiak ${ }^{3}$, Hanna Ćwiek-Kupczyńska ${ }^{4}$, Paweł Krajewski ${ }^{4}$, \\ Tomasz Książczyk ${ }^{1}$ and Zbigniew Zwierzykowski ${ }^{1}$
}

\begin{abstract}
Background: Species of the Festuca and Lolium genera, as well as intergeneric Festuca $\times$ Lolium (Festulolium) hybrids, are valuable fodder and turf grasses for agricultural and amenity purposes worldwide. Festulolium hybrids can merge in their genomes agronomically important characteristics. However, in polyploid plants, especially in allopolyploids, the hybridization of divergent genomes could contribute to various abnormalities, such as variability in chromosome number, structural rearrangements, and/or disorders in inheritance patterns. Here we studied these issues in allotetraploid Festuca pratensis $\times$ Lolium perenne hybrids.
\end{abstract}

Results: Cytogenetic procedures, including fluorescent in situ hybridization, genomic in situ hybridization, and molecular markers - inter-simple sequence repeats (ISSR) were exploited. This cytogenetic approach indicated the dynamics in the number and distribution of ribosomal RNA genes and structural rearrangements for both parental genomes (Festuca and Lolium) in hybrid karyotypes. The separate analysis of F. pratensis and L. perenne chromosomes in hybrid plants ( $F_{2}-F_{3}$ generations of $F$. pratensis $\times$ L. perenne) revealed the asymmetrical level of rearrangements. Recognized structural changes were mainly located in the distal part of chromosome arms, and in chromosomes bearing ribosomal DNA, they were more frequently mapped in arms without this sequence. Based on the ISSR markers distribution, we found that the tetrasomic type of inheritance was characteristic for the majority of ISSR loci, but the disomic type was also observed. Nonetheless, no preference in the transmission of either Festuca or Lolium alleles to the following generations of allotetraploid F. pratensis $\times$ L. perenne hybrid was observed.

Conclusion: Our study reports cytogenetic and molecular genotyping of the F. pratensis $\times L$. perenne hybrid and its following $F_{2}-F_{3}$ progenies. The analysis of 137 allotetraploid $F$. pratensis $\times L$. perenne hybrids revealed the higher level of recombination in chromosomes derived from F. pratensis genome. The results of ISSR markers indicated a mixed model of inheritance, which may be characteristic for these hybrids.

Keywords: Festuca, Festulolium hybrids, Lolium, Genomic composition, Inheritance pattern, Rearrangements, Recombination

\section{Background}

Polyploids frequently occur within the plant kingdom, especially in domesticated and economically important plants in the world [1]. Within polyploids, two basic types auto- and allopolyploids are usually. Genomes of allopolyploids contain chromosome sets from two or

\footnotetext{
* Correspondence: jcho@igr.poznan.pl

${ }^{1}$ Department of Environmental Stress Biology, Institute of Plant Genetics,

Polish Academy of Sciences, Poznań, Poland

Full list of author information is available at the end of the article
}

more divergent genomes of donor plants. In the course of evolution, plant genomes underwent various processes that had an impact on numerical and structural changes $[2,3]$. The comparison of karyotypes within the grass family and various genera revealed vast variability in the chromosome number and in their morphology. There are three different levels of changes that may occur in the hybrid genomes: (i) DNA sequence (e.g., allelic differences caused by nucleotide substitutions or indels), (ii) structure and gene order (e.g., chromosomal

(c) The Author(s). 2019 Open Access This article is distributed under the terms of the Creative Commons Attribution 4.0 International License (http://creativecommons.org/licenses/by/4.0/), which permits unrestricted use, distribution, and reproduction in any medium, provided you give appropriate credit to the original author(s) and the source, provide a link to the Creative Commons license, and indicate if changes were made. The Creative Commons Public Domain Dedication waiver (http://creativecommons.org/publicdomain/zero/1.0/) applies to the data made available in this article, unless otherwise stated. 
rearrangements), and (iii) total number of chromosomes in the complement. In allopolyploids, especially in the newly formed, smaller (at DNA sequence level) and larger (at chromosome level) genetic changes could result from recombination between homoeologous chromosomes. Pairing affinity and chiasmata formation between homoeologous chromosome sets have an enormous impact on inheritance patterns [4-6]. Importantly, several gametophytic and zygotic barriers have been reported, which caused deviation of allele frequencies from Mendelian ratios, for example in the interspecific crosses in rice [7].

Variation in a number of chromosomes and/or in their structure are pivotal issues in the crossing of plants derived from different genera. Plants with the expected chromosome number, as well as aneuploids may be observed within the hybrid's progeny [8-10]. Recombinant chromosomes can be characterized using molecular and cytogenetic tools, such as genetic markers (e.g. [11, 12]) and genomic in situ hybridization (GISH) technique (e.g. $[9,13-17])$. The application of GISH, usually combined with fluorescent in situ hybridization (FISH), enables the characterization of the genome composition of hybrid plants providing valuable information for breeding new cultivars on the early stages of material selection.

Lolium species (L. perenne and L. multiflorum), the major source of forage in temperate regions of the world, depict the considerable variation of quality traits, crucial implication for grass breeding programs. This group of plants is characterized by high digestibility, palatability and intensive spring growth [18]. Traits which are of great importance for adaptation to abiotic as well as biotic stresses, e.g. drought tolerance, winter hardiness and resistance to fungal diseases, are provided by Festuca species (F. pratensis and F. arundinacea) [18]. Desirable traits from Lolium species can be merged with features of Festuca species through crosses and production of intergeneric Festuca $\times$ Lolium hybrids (Festulolium). Chromosomes of these hybrids can recombine at high frequency $[9,11,19]$.

The main aims of this study were the examination of the genomic composition of $F$. pratensis $\times L$. perenne hybrid and its following generations $\left(\mathrm{F}_{2}-\mathrm{F}_{3}\right)$ and the determination of inheritance pattern in this plant material. To achieve these goals, we applied the cytogenetic procedures, including FISH with ribosomal DNA (rDNA) sequences to recognize selected chromosomes in the complements, GISH to analyze the genomic architecture, and molecular markers - inter-simple sequence repeats (ISSR) to determine the types of ISSR loci inheritance in three successive generations of $F$. pratensis $\times L$. perenne.

\section{Results}

Karyotype analysis of $F$. pratensis $\times L$. perenne hybrids In total, 134 plants of $F_{2}$ (combinations no. 1 and 2) and $\mathrm{F}_{3}$ (combinations no. 3 and 4 ) generations were analyzed (see Additional file 1: Figure S1) and the majority of them were tetraploid with $2 \mathrm{n}=4 \mathrm{x}=28$ (83.3\% in $\mathrm{F}_{2}$ and $68.2 \%$ in $\left.\mathrm{F}_{3}\right)$. Among aneuploid plants, both hypoploids $(2 \mathrm{n}=26$, 27) and hyperploids $(2 \mathrm{n}=29,30,31)$ were recorded. Hypoploids constituted $11.1 \%$ in $\mathrm{F}_{2}$ and $25 \%$ in $\mathrm{F}_{3}$, while hyperploids $-5.6 \%$ and $6.8 \%$, respectively (Figs. 1,2 ).

Allotetraploid plants with 14 chromosomes of F. pratensis and 14 chromosomes of $L$. perenne were distinguished in $56 \%$ of $\mathrm{F}_{2}$ and $40 \%$ of $\mathrm{F}_{3}$ generation. Within the remaining plants with 28 chromosomes, the genotypes with the higher number of $L$. perenne chromosomes were predominated (29.3\% in $\mathrm{F}_{2}$ and $53.3 \%$ in $\mathrm{F}_{3}$ ). Plants with lower $(2 n<28)$ and higher $(2 n>28)$ total number of chromosomes, that constituted $16.7 \%$ in $\mathrm{F}_{2}$ and $31.8 \%$ in $F_{3}$, were also characterized by the higher number of L. perenne chromosomes (average $43.3 \%$ for both generations) (see Additional file 2: Table S1).

\section{rDNA-FISH mapping}

rDNA-FISH mapping revealed that $F$. pratensis and $L$. perenne species, used to obtain $\mathrm{F}_{1}$ hybrids, had four loci of $5 \mathrm{~S}$ rDNA. In the case of $35 \mathrm{~S}$ rDNA, four and 15 loci were recorded, respectively. Among $\mathrm{F}_{1}$ plants, $5 \mathrm{~S}$ rDNA sequence was mapped to four chromosomes in the genomes of maternal plant and both pollinators. Whereas $35 \mathrm{~S}$ rDNA was hybridized to eight sites in the karyotype of pollinator 6-7A and nine sites in the female plant and pollinator 6-3B (Fig. 1). Four $\mathrm{F}_{2}$ plants used to produce two combinations of $F_{3}$ (no. 3 and 4 ) were characterized by four loci of $5 \mathrm{~S}$ rDNA and eight loci of $35 \mathrm{~S} \mathrm{rDNA}$ (combination no. 3), as well as four loci of 5S rDNA and nine loci of $35 \mathrm{~S}$ rDNA (combination no. 4) (Fig. 2). Among $\mathrm{F}_{2}$ progeny, the number of $5 \mathrm{~S}$ rDNA loci was equal to four, except for one plant with five loci of this sequence (Fig. 1b). This sequence was located in an interstitial part of chromosome $3 \mathrm{~F}$ and near the centromeric region of chromosome $3 \mathrm{~L}$. In the vast majority of $\mathrm{F}_{2}$ individuals, there were two pairs of each chromosome types, in minority three chromosomes $3 \mathrm{~F}$ and only one chromosome 3L (see Additional file 2: Table S1). The similar trend was observed among $\mathrm{F}_{3}$ plants - the number of $5 \mathrm{~S}$ rDNA equaled four, with the exception of one plant with three loci of $5 \mathrm{~S}$ rDNA (Fig. 2b). In all $\mathrm{F}_{3}$ analyzed hybrids, two chromosomes $3 \mathrm{~F}$ and two $3 \mathrm{~L}$ were mostly observed. Only for several plants, three $3 \mathrm{~F}$ and one $3 \mathrm{~L}$ chromosomes as well as conversely one $3 \mathrm{~F}$ and three $3 \mathrm{~L}$ chromosomes were recorded (Fig. 2). In the karyotype of plants with three loci of $5 \mathrm{~S}$ rDNA, one chromosome $3 \mathrm{~F}$ and two chromosomes $3 \mathrm{~L}$ were observed, while for the karyotype with five loci of this sequence three $3 \mathrm{~F}$ and two 3L chromosomes were noticed.

The number of $35 \mathrm{~S}$ rDNA sequence was more variable and ranged from seven to eleven loci in $F_{2}$ and $F_{3}$ plants (Figs. 1, 2). This sequence was located at the secondary 

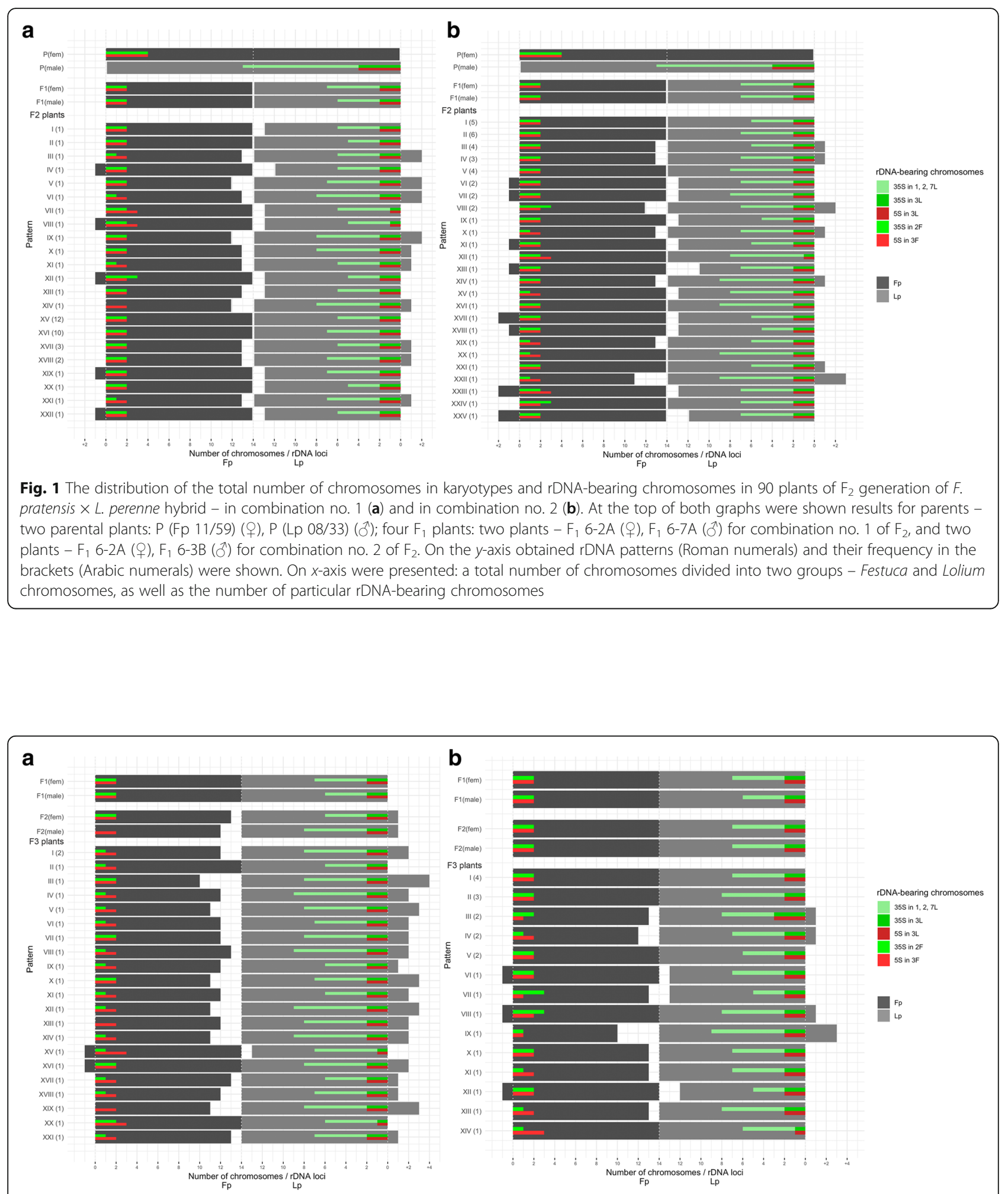

Fig. 2 The distribution of the total number of chromosomes in karyotypes and rDNA-bearing chromosomes in 44 plants of $F_{3}$ generation of $F$. pratensis $\times$ L. perenne hybrid - in combination no. $3(\mathbf{a})$, and in combination no. 4 (b). At the top of both graphs were shown results for parents -

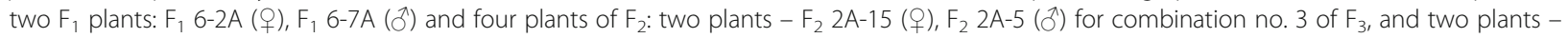
$\mathrm{F}_{2} 2 \mathrm{~A}-27$ (P), $\mathrm{F}_{2} 2 \mathrm{~A}-12$ (ठ) for combination no. 4 of $\mathrm{F}_{3}$. On the $y$-axis obtained rDNA patterns (Roman numerals) and their frequency in the brackets (Arabic numerals) were shown. On $x$-axis were presented: a total number of chromosomes, divided into two groups - Festuca and Lolium chromosomes, as well as the number of particular rDNA-bearing chromosomes 
constriction regions of $2 \mathrm{~F}$ and $3 \mathrm{~L}$ chromosomes, as well as on the chromosomes 1, 2 and 7L. In both generations, the variation in the number of particular chromosomes was as follows: 3-7 signals for chromosomes 1, 2, 7L, 1-3 for chromosomes 3L, and 0-3 for chromosomes 2F (Figs. $1,2)$.

With regard to the type and the number of recognized rDNA-bearing chromosome pairs, the analysis showed 22 and 25 various rDNA patterns in combination no. 1 and 2 of $F_{2}$ generation, respectively (Fig. 1). Whereas in $\mathrm{F}_{3}$ generation for combinations no. 3 and no. 4, subsequently 21 and 14 rDNA patterns were detected (Fig. 2). The most frequent patterns $(48.9 \%)$ in $\mathrm{F}_{2}$ combination no. 1 reflected rDNA arrangements occurring in parental plants. In the remaining $F_{2}$ and $F_{3}$ plants, different rDNA profiles were identified. However, the most repeated patterns were connected with one more or one less $35 \mathrm{~S}$ rDNA locus. The analysis of the total number of rDNA-bearing chromosomes for all $\mathrm{F}_{2}$ and $\mathrm{F}_{3}$ analyzed plants revealed that even number of chromosomes prevailed, what was expected, however, with the exception of the number of chromosomes $2 \mathrm{~F}$. In $\mathrm{F}_{3}$ combination no. 3, almost $70 \%$ of plants had in karyotype only one chromosome 2F (Fig. 2).

\section{GISH mapping}

To reveal rearrangements in the karyotypes of $F$. pratensis $\times$ L. perenne hybrids, the analysis with total genomic DNA (GISH) was performed and this approach did not reveal any structural changes in $F_{1}$ plants. The $F_{2}$ and $F_{3}$ progenies of the $F$. pratensis $\times L$. perenne hybrid were characterized by karyotype rearrangements. Their number increased from generation to generation and was as follows: 179 for $F_{2}$ plants and 217 for $F_{3}$ plants (see Additional file 2: Table S1). These numbers include the terminal, interstitial and pericentromeric types of rearrangements in total. The rearranged chromosomes were divided into two groups consisting of rearranged rDNA-bearing chromosomes and rearranged nonrDNA-bearing ones. The level of rearrangements in rDNA-bearing chromosomes equaled $38.8 \%$ in $\mathrm{F}_{2}$ and $47 \%$ in $\mathrm{F}_{3}$ generation, while in non-rDNA-bearing chromosomes $61.2 \%$ and 53\%, respectively. Among identified rearrangements, terminal (92.2\%), interstitial (7.1\%) and pericentromeric (0.7\%) types were recognized. Non-rDNA-bearing chromosomes were more frequent $\left(61.4 \%\right.$ in $F_{2}$ and $63.2 \%$ in $\left.F_{3}\right)$ in the group of non-recombined chromosomes (see Additional file 2: Table S1).

The separate analysis of rearranged chromosomes derived from $F$. pratensis and $L$. perenne genomes revealed that the number of recombined rDNA-bearing chromosomes was on a similar level for $\mathrm{F}_{2}$ plants, $51.7 \%$ and $48.3 \%$ for $F$. pratensis and $L$. perenne genome, respectively. More differences were found in $\mathrm{F}_{3}$ generation, $40.4 \%$ for $F$. pratensis and $59.6 \%$ for L. perenne. When both generations were analyzed together, slightly predominance of the rearranged rDNA-bearing chromosomes of L. perenne (55.5\%) was observed. On the other hand, in non-rDNA-bearing chromosomes, the higher level of recombination was detected for $F$. pratensis chromosomes $\left(67.2 \%\right.$ in $\mathrm{F}_{2}$ and $76.7 \%$ in $\left.\mathrm{F}_{3}\right)$. Additionally, among analyzed plants with detected structural rearrangements, several genotypes with the uncommon location of changes were noticed. In these plants, the rearrangements colocalized with the position of rDNA locus (5S and $35 \mathrm{~S}$ rDNA) in various type of rDNA-bearing chromosomes - chromosome 3L/non-rDNA-bearing Festuca chromosome (Fig. 3a and b), chromosome 2F (Fig. 3c and d), and chromosomes 1, 2, 7L (Fig. 3e and f). The similar position of rearrangement was also detected in chromosome 3F. Furthermore, an $\mathrm{F}_{2}$ plant without two $2 \mathrm{~F}$ chromosomes was observed (Fig. $3 g$ and $\mathrm{h}$ ).

The detailed analysis of recombined rDNA-bearing chromosomes in $\mathrm{F}_{2}$ and $\mathrm{F}_{3}$ plants unveiled the types and the frequency of observed changes. Rearranged regions were mostly located in the arms without rDNA-marker for both parental genomes and both generations and they always were located in the distal parts of chromosomes (Fig. 4). In $F_{2}$ plants, the most recombined types were: chromosomes $2 \mathrm{~F}$ and the group of chromosomes 1 , $2,7 \mathrm{~L}$, while in $\mathrm{F}_{3}$ - the group of chromosomes $1,2,7 \mathrm{~L}$ and chromosomes 3F (see Additional file 2: Table S1). However, the types of rearrangements and their frequencies in the group of chromosomes 1,2,7L were not shown in Fig. 4, because the location of $35 \mathrm{~S}$ rDNA and similar size of chromosomes do not allow to distinguish them, therefore we could not determine precisely the type and the frequency of changes in each pair of chromosomes separately. In the $F_{2}$ generation, the highest level of recombination was recorded for $35 \mathrm{~S}$ rDNA-bearing arm of chromosomes $3 \mathrm{~L}$. In the $\mathrm{F}_{3}$ generation, however, more rearrangements were found in the opposite location - in arm bearing $5 \mathrm{~S}$ rDNA sequence. For chromosomes $2 \mathrm{~F}$ and $3 \mathrm{~F}$, the majority of changes in the arms without rDNA landmarks were occurred (Fig. 4).

\section{Statistical analysis of cytogenetic traits}

Statistical analysis of selected cytogenetic traits in $F_{2}$ generation revealed weakly significant differences between distributions and strongly significant differences between mean values for the number of 35S rDNA in $L$. perenne genome what is related to the number of chromosomes 1, 2, 7L (Table 1). The analysis of $\mathrm{F}_{2}$ plants and the comparison between $F_{2}$ and $F_{3}$ generations revealed the statistically significant differences for the number of non-rDNA-bearing chromosomes 


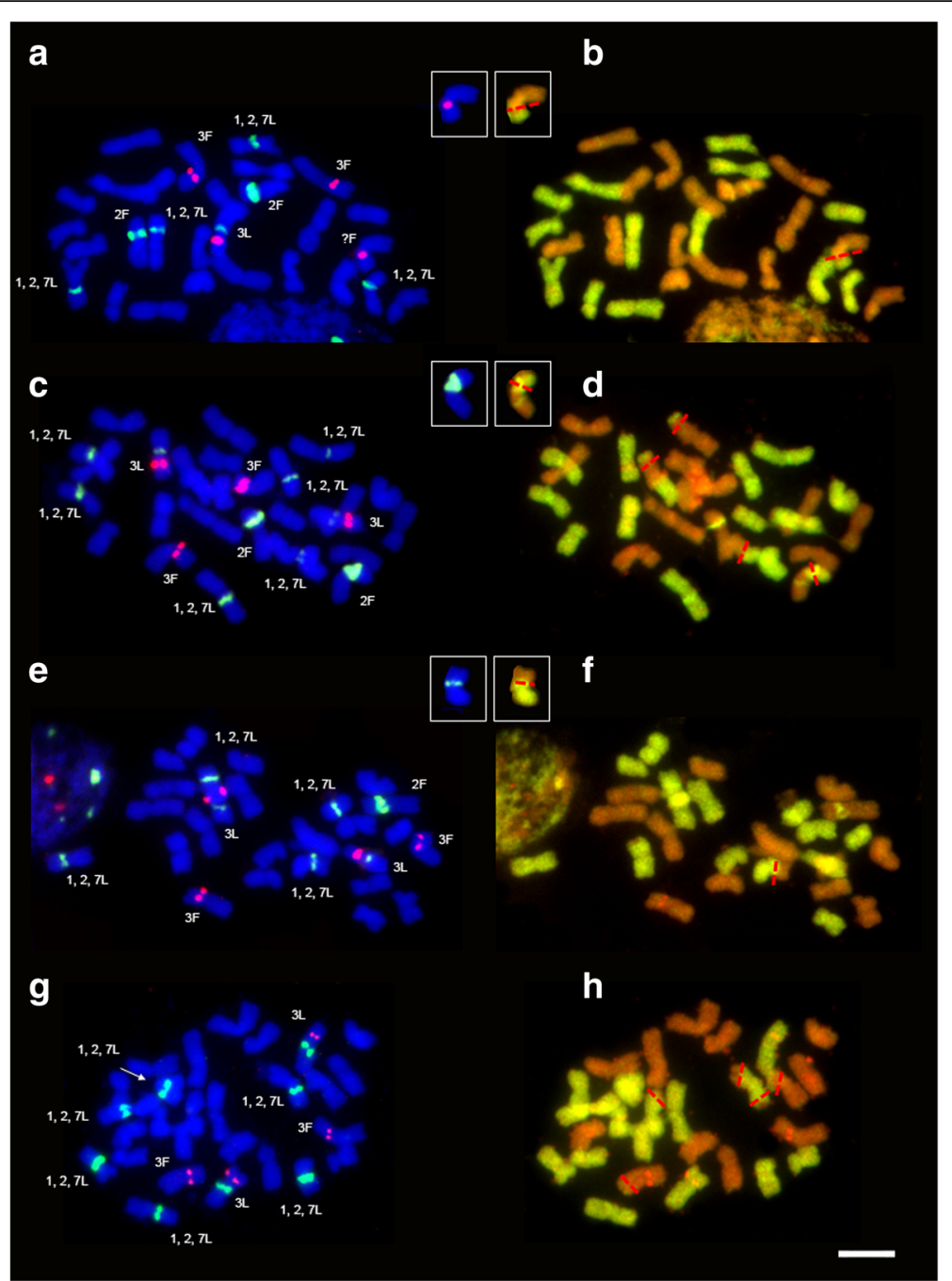

Fig. 3 Rearrangements in rDNA-bearing chromosomes among F. pratensis $\times L$. perenne hybrids. (a, b) $F_{2} 2 A-33$ with recombined 3L/non-rDNAbearing Festuca chromosome; (c, d) $F_{2} 2 B-21$ with recombined $2 \mathrm{~F}$ chromosome; (e, f) $F_{2} 2 B-28$ with recombined one of 1, 2, $7 \mathrm{~L}$ group of chromosomes, and ( $\mathbf{g}, \mathbf{h}) \mathrm{F}_{2} 2 \mathrm{~A}-5$ without $2 \mathrm{~F}$ chromosomes. (a, $\left.\mathbf{c}, \mathbf{e}, \mathbf{g}\right) \mathrm{FISH}$ with $5 \mathrm{~S}$ rDNA (red) and $35 \mathrm{~S}$ rDNA (green); chromosomes were counterstained with DAPI (blue). (b, $\mathbf{d}, \mathbf{f}, \mathbf{h}$ ) GISH with total genomic DNA of L. perenne as a probe (green) and with blocking genomic DNA of F. pratensis (orange) on the same metaphase plate; chromosomes were counterstained with propidium iodide (orange). Red dotted lines indicate the place of rearrangement. Chromosomes with rearrangements corresponding with rDNA position were exemplified in the insets. Scale bar $5 \mu m$

(Tables 1 and 2). In comparison between generations, it was also revealed that the statistically significant difference existed for the number of $35 \mathrm{~S}$ rDNA in $F$. pratensis genome what is related to the number of chromosomes 2F (Table 2).

We also studied separately the chromosomes derived from $F$. pratensis and $L$. perenne genomes, divided into groups: rearranged and non-rearranged, as well as rDNA-bearing and non-rDNA-bearing chromosomes. Rearranged chromosomes with rDNA sequence, were subdivided into two classes based on the location of rearrangements - in the arm with rDNA and without rDNA landmark (Table 3). Statistical differences were observed among $F_{2}$ and $F_{3}$ generations for non- recombined rDNA-bearing and non-rDNA-bearing chromosomes for both $F$. pratensis and L. perenne, as well as for recombined non-rDNA-bearing chromosomes of both genomes, but only for $\mathrm{F}_{3}$ generation. In this analysis, we also considered the comparison between analyzed generations. Statistically significant differences were identified for non-recombined rDNA-bearing chromosomes of both genomes and non-recombined non-rDNA-bearing chromosomes of $F$. pratensis genome, as well as for the number of recombined rDNA- and non-rDNA-bearing chromosomes for both genomes (Table 3). Additionally, the analysis of rearrangement locations revealed statistically significant differences in arms without rDNA markers (Table 3). 


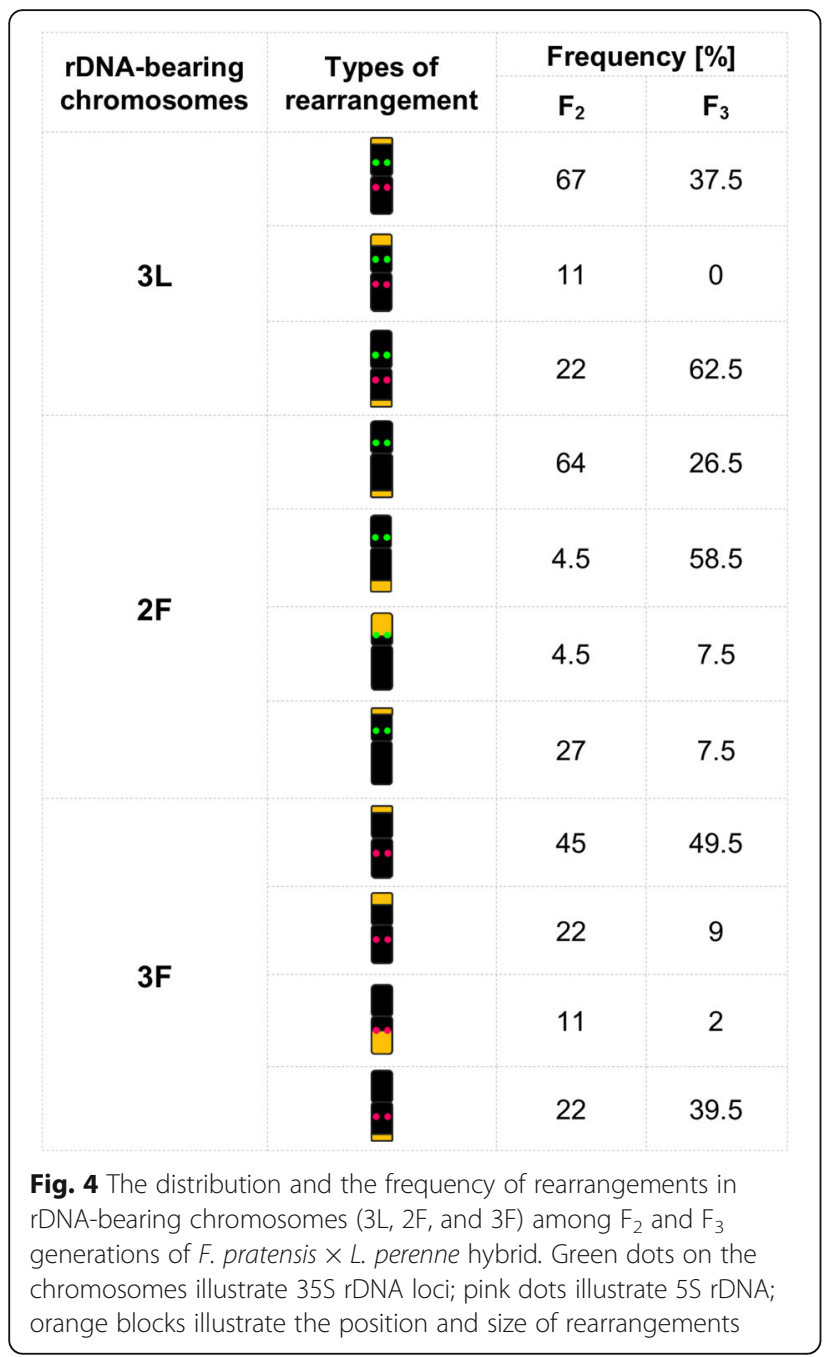

\section{ISSR loci polymorphism between parental plants}

The ISSR analysis resulted in a reliable amplification of 71 loci in parental plants (F. pratensis and L. perenne). The total number of loci amplified in subsequent generations was lower due to the occurrence of recessive genotypes in both $F_{1}$ and $F_{2}$ parental individuals. Each ISSR primer produced markers with similar informativeness, as calculated by Polymorphism Information Content (PIC) for each of the parental, $F_{1}$ and $F_{2}$ individuals, as well as for each of $F_{2}$ and $F_{3}$ cross combinations (see Additional file 3: Table S2). The highest level of polymorphism, accounted for nearly $72 \%$ of loci, was observed between $F$. pratensis and L. perenne parental forms. The frequency of polymorphic loci in $F_{1}$ generation was lower than in parental forms, although the individuals used for combination no. 2 were more polymorphic compared with the parental individuals of combination no. 1. Similarly, the polymorphism between individuals from $\mathrm{F}_{2}$ generation was further reduced, but $\mathrm{F}_{2}$ parents used for combination no. 4 showed more diversity than those used for combination no. 3 (Table 4). This finding was also reflected by the mean values of PIC, which showed that ISSR markers detected in the parents of cross combination 2 and 4 were more informative, and as a result higher mean value of PIC was also found for the progeny of these cross combinations (see Additional file 3: Table S2).

\section{Segregation of ISSR loci in $F_{2}$ and $F_{3}$ generations}

More than one type of the segregation ratio passed the $X^{2}$ test in the majority of ISSR loci (43 loci) in the combination no. 1 of $F_{2}$ generation (see Additional file 4: Table S3). For 25 loci only one, non-distorted segregation ratio was noticed and in the case of two loci a segregation distortion was found. Additionally, one locus passed the $X^{2}{ }_{13: 15}$ test, indicating its tetrasomic inheritance and the possibility of quadrivalents formation and random chromatid segregation. In the $F_{2}$ combination no. 2, different proportion of each of those categories was recorded: for 33 loci only one non-distorted segregation type was found, in case of 27 loci more possibilities were detected and 11 ISSR loci showed distorted segregation (see Additional file 5: Table S4). Regardless of the above differences, similar proportions of particular inheritance types of ISSR loci were found in both $\mathrm{F}_{2}$ combinations. The tetrasomic inheritance was significantly prevailing over the disomic inheritance. Furthermore, the $X^{2}$ test results suggested that three loci (L7_300, L8_300, and L8_1400) have been inherited according to a different model in both $\mathrm{F}_{2}$ combinations (see Additional file 6: Table S5). Importantly, it was not possible to reliably assign the inheritance type to the majority of loci what may somehow bias these calculations (Table 5, see Additional file 6: Table S5). In these loci where distorted segregation was detected, the comparable proportion was skewed toward a dominant or recessive allele. In half of these cases, it was possible to point to the prevalence of the allele from specific parental species, and again similar proportion of distorted loci were skewed toward Festuca or Lolium allele, respectively (see Additional file 6: Table S5).

The similar analysis of $\mathrm{F}_{3}$ generation gave much less reliable results. This was caused by a significantly lower ISSR polymorphism between $\mathrm{F}_{2}$ plants taken as parents for the crosses. In the majority of loci, both lines were characterized by the presence of ISSR band making the genotype assignment more difficult. In addition, in 12 and 11 loci no bands amplification was observed in combination no. 3 and 4 of $F_{3}$, respectively. The great majority of loci showed more than one possible segregation ratio in both $\mathrm{F}_{3}$ combinations (49 and 45 loci, for combinations no. 3 and 4, respectively). Three loci had distorted segregation in the combination no. 3 - one locus was skewed toward the recessive allele and two toward 


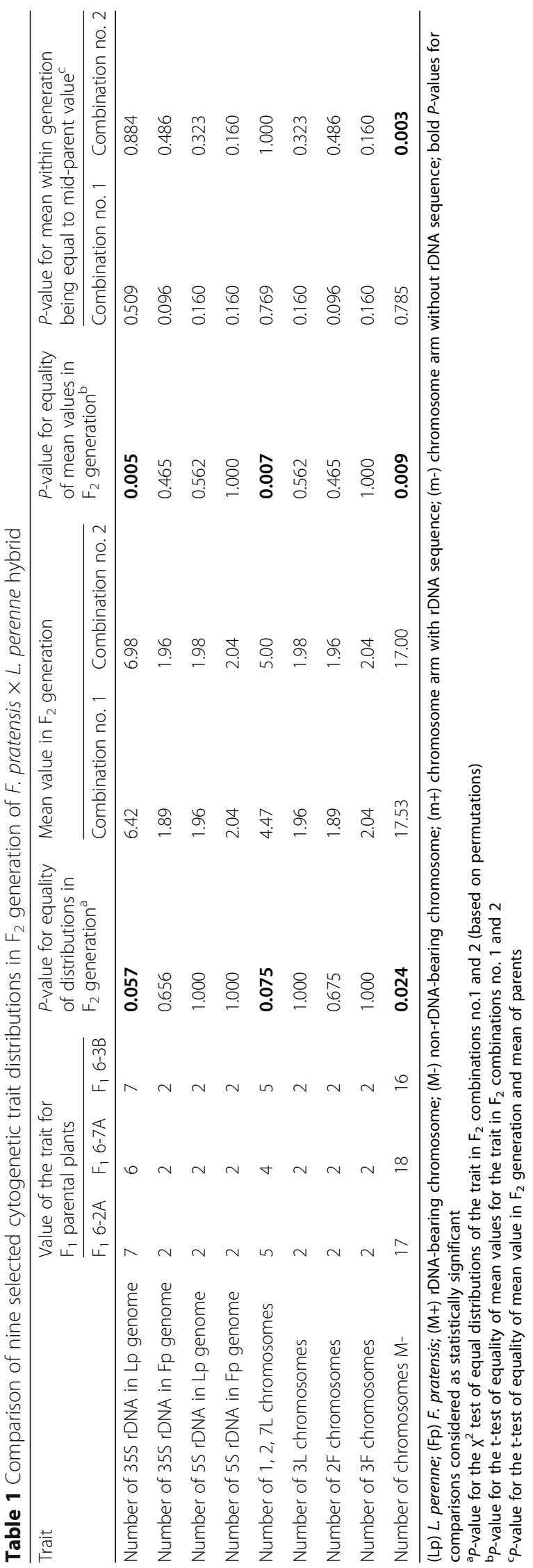


Table 2 Comparison of nine selected cytogenetic trait distributions in $F_{2}$ and $F_{3}$ generations of $F$. pratensis $\times L$. perenne hybrid

\begin{tabular}{|c|c|c|c|c|c|c|c|c|}
\hline \multirow[t]{2}{*}{ Trait } & \multicolumn{4}{|c|}{ Value of the trait for $F_{2}$ parental plants } & \multirow{2}{*}{$\begin{array}{l}P \text {-value for } \\
\text { equality of } \\
\text { distributions } \\
\text { in } F_{2} \text { and } F_{3} \\
\text { plants }\end{array}$} & \multicolumn{2}{|c|}{ Mean value in generation } & \multirow{2}{*}{$\begin{array}{l}\text { P-value for } \\
\text { equality of } \\
\text { mean value } \\
\text { in } F_{2} \text { and } F_{3} \\
\text { plants }\end{array}$} \\
\hline & $2 \mathrm{~A}-15$ & $2 A-5$ & $2 \mathrm{~A}-27$ & $2 \mathrm{~A}-12$ & & $\mathrm{~F}_{2}$ & $\mathrm{~F}_{3}$ & \\
\hline Number of $35 \mathrm{~S}$ rDNA in Lp genome & 6 & 8 & 7 & 7 & 0.002 & 6.42 & 7.32 & $<0.001$ \\
\hline Number of $35 \mathrm{~S}$ rDNA in Fp genome & 2 & 0 & 2 & 2 & $<0.001$ & 1.89 & 1.46 & $<0.001$ \\
\hline Number of $5 S$ rDNA in Lp genome & 2 & 2 & 2 & 2 & 0.239 & 1.96 & 1.98 & 0.718 \\
\hline Number of $5 S$ rDNA in Fp genome & 2 & 2 & 2 & 2 & 0.123 & 2.04 & 1.98 & 0.328 \\
\hline Number of $1,2,7 \mathrm{~L}$ chromosomes & 4 & 6 & 5 & 5 & $<0.001$ & 4.47 & 5.32 & $<0.001$ \\
\hline Number of $3 \mathrm{~L}$ chromosomes & 2 & 2 & 2 & 2 & 0.245 & 1.96 & 1.98 & 0.718 \\
\hline Number of $2 \mathrm{~F}$ chromosomes & 2 & 0 & 2 & 2 & $<0.001$ & 1.89 & 1.48 & $<0.001$ \\
\hline Number of $3 \mathrm{~F}$ chromosomes & 2 & 2 & 2 & 2 & 0.105 & 2.04 & 1.98 & 0.328 \\
\hline Number of chromosomes M- & 18 & 17 & 17 & 17 & 0.040 & 17.53 & 17.11 & 0.027 \\
\hline
\end{tabular}

(Lp) L. perenne; (Fp) F. pratensis; (M+) rDNA-bearing chromosome; (M-) non-rDNA-bearing chromosome; (m+) chromosome arm with rDNA sequence; (m-) chromosome arm without rDNA sequence; bold $P$-values for comparisons considered as statistically significant

the dominant one. Five loci were distorted in the combination no. 4 - here four were skewed toward recessive allele and only one toward the dominant allele. In case of two loci, it was possible to point to the prevalence of the allele from specific parental species and in both of them, the distortion was toward Lolium allele (see Additional file 7: Table S6 and Addititional file 8: Table S7). When the occurrence of distorted loci was compared between $F_{2}$ and $F_{3}$ generation no specific pattern was noticed. Only one locus with distorted segregation in $F_{2}$ generation was further distorted in the $F_{3}$. In the remaining loci, no co-occurrence of such events in both generations was found. Moreover, the ISSR analysis of $F_{3}$ generation did not allow to discover the inheritance type for the vast majority of loci (Table 5, see Additional file 9: Table S8).

In addition to the above analysis, the distribution of the frequencies of the most probable genotypes that was inferred based on ISSR loci segregation was provided (Fig. 5). It shows the gradual prevalence of dominant allele frequency in subsequent generations. Such observation may further support the tetrasomic type of ISSR inheritance, as in this type the dominant class is usually much numerous than the recessive class for the same cross combination of parental genotypes. It may also reflect the process of more frequent transmission of a dominant allele from generation to generation.

Table 3 Comparison of distributions of selected cytogenetic traits (recombined and non-recombined chromosomes belonging to F. pratensis and L. perenne genomes) within and between $F_{2}$ and $F_{3}$ generations of $F$. pratensis $\times$ L. perenne hybrid

\begin{tabular}{|c|c|c|c|}
\hline Trait & $\begin{array}{l}\text { Comparison } F_{2} \text { combination } \\
\text { no. } 1 \text { vs. } F_{3} \text { generation }\end{array}$ & $\begin{array}{l}\text { Comparison Lp vs. } \\
F p \text { in } F_{2} \text { generation }\end{array}$ & $\begin{array}{l}\text { Comparison Lp vs. } \\
\mathrm{Fp} \text { in } \mathrm{F}_{3} \text { generation }\end{array}$ \\
\hline Lp chromosomes - non-recombined M+ & 0.023 & $<0.001$ & $<0.001$ \\
\hline Fp chromosomes - non-recombined $\mathrm{M}+$ & $<0.001$ & & \\
\hline Lp chromosomes - non-recombined M- & 0.502 & $<0.001$ & 0.020 \\
\hline Fp chromosomes - non-recombined M- & 0.004 & & \\
\hline Lp chromosomes - recombined M+ & $<0.001$ & 1.000 & 0.201 \\
\hline Fp chromosomes - recombined $\mathrm{M}+$ & 0.002 & & \\
\hline Lp chromosomes - recombined M- & 0.020 & 0.550 & $<0.001$ \\
\hline Fp chromosomes - recombined M- & $<0.001$ & & \\
\hline Lp chromosomes - arm recombined m+ & 0.133 & 0.185 & 0.020 \\
\hline Fp chromosomes - arm recombined m+ & 0.888 & & \\
\hline Lp chromosomes - arm recombined m- & $<0.001$ & 0.167 & 0.357 \\
\hline Fp chromosomes - arm recombined m- & 0.002 & & \\
\hline
\end{tabular}

(Lp) L. perenne; (Fp) F. pratensis; (M+) rDNA-bearing chromosome; (M-) non-rDNA-bearing chromosome; (m+) chromosome arm with rDNA sequence; (m-) chromosome arm without rDNA sequence; bold $P$-values for comparisons considered as statistically significant 
Table 4 ISSR polymorphism between parental species - $F$. pratensis and $L$. perenne and between pairs of the $F_{1}$ and $F_{2}$ plants used as parents for subsequent generations of $F$. pratensis $\times L$. perenne hybrid

\begin{tabular}{llll}
\hline Compared genotypes & $\begin{array}{l}\text { No. of } \\
\text { monomorphic } \\
\text { loci }\end{array}$ & $\begin{array}{l}\text { No. of } \\
\text { polymorphic } \\
\text { loci }\end{array}$ & $\begin{array}{l}\text { Polymorphism } \\
{[\%]}\end{array}$ \\
\hline Fp 11/59 and Lp 08/33 & 20 & 51 & 71.83 \\
$F_{1}$ 6-2A and $F_{1}$ 6-7A & 51 & 15 & 22.72 \\
$F_{1}$ 6-2A and $F_{1}$ 6-3B & 37 & 30 & 44.77 \\
$F_{2}$ 2A-15 and $F_{2}$ 2A-5 & 55 & 5 & 8.33 \\
$F_{2}$ 2A-27 and $F_{2}$ 2A-12 & 51 & 8 & 13.55 \\
\hline
\end{tabular}

\section{Discussion}

The formation of new synthetic allopolyploid plants via hybridization of different species can include: chromosomal rearrangements $[17,20]$, transposon activations [21-23], changes in rDNA loci [24, 25] and/or loss of DNA [26-28]. In allopolyploids, like allotetraploid $F$. pratensis $\times$ L. perenne hybrids, in which two genomes/ species from different genera are merged, the deciphering of those processes is crucial to produce more persistent high-quality grass cultivars. For that purpose, the comprehensive analysis, including the examination of genome composition and structural reshufflings, the segregation of ISSR loci and their inheritance patterns in $\mathrm{F}_{2}-\mathrm{F}_{3}$ generations of allotetraploid $F$. pratensis $\times L$. perenne hybrid was performed.

\section{Genomic structure of hybrids}

In rDNA-FISH experiments, the same number and distribution of $5 \mathrm{~S}$ rDNA were observed in the vast majority of studied $F_{2}$ and $F_{3}$ generations (in 131 out of 134 plants). Only in three plants, the lower or higher number of $5 \mathrm{~S}$ rDNA loci was found. Nonetheless, this phenomenon was related to the changed total number of chromosomes in the complement. The more considerable variation was noticed for the number of $35 \mathrm{~S}$ rDNA that ranged from seven to eleven loci in $F_{2}$ and $F_{3}$ plants, and the statistical analysis of this trait revealed significant differences between both generations, especially for the number of chromosomes 1, 2, 7L and 2F. It

Table 5 Number of ISSR loci that showed particular inheritance type in $F_{2}$ and $F_{3}$ generations of $F$. pratensis $\times L$. perenne hybrid

\begin{tabular}{llll}
\hline Cross combination & No. of loci & & \\
\cline { 2 - 4 } & $\begin{array}{l}\text { Disomic } \\
\text { inheritance }\end{array}$ & $\begin{array}{l}\text { Tetrasomic } \\
\text { inheritance }\end{array}$ & Unknown \\
\hline$F_{2}$ combination no. 1 & 3 & 19 & 49 \\
$F_{2}$ combination no. 2 & 5 & 18 & 48 \\
$F_{3}$ combination no. 3 & 2 & 0 & 58 \\
$F_{3}$ combination no. 4 & 0 & 2 & 57 \\
\hline
\end{tabular}

has been observed for many different plant species and hybrids that the number of $5 \mathrm{~S}$ rDNA is stable, whereas $35 \mathrm{~S}$ rDNA sequence seems to be more polymorphic [29, 30], what reflects showed rDNA patterns among studied F. pratensis $\times$ L. perenne hybrids. Nevertheless, Książczyk et al. [17] described the unstable number (from four to six hybridization signals) of $5 \mathrm{~S}$ rDNA in $\mathrm{F}_{2}-\mathrm{F}_{4}$ generations of $F$. pratensis $\times L$. perenne hybrid. In this plant material, the additional smaller hybridization sites were located in different regions of $F$. pratensis chromosomes and this was not related to the changed total number of chromosomes. Pedrosa-Harand et al. [31] suggested that variability in chromosomal positions, numbers and signal sizes of rDNA can be caused by at least three different mechanisms: ( $i$ ) structural rearrangements that affect the position of rDNA loci; (ii) amplification of satellite DNA with no impact on the order of other sequences in chromosomes; and (iii) dispersion of rDNA repeats, amplification of the new minor loci and deletion of original major loci. The first two mechanisms are connected with changes in the chromosomal position of rDNA sequences, and the third one is responsible for changing the number and size of rDNA loci. Chromosomal re-patterning can be also connected with mobile elements activity [32], such as - Enhancer/Suppressor-mutator $(\mathrm{En} / \mathrm{Spm})$ transposons in Aegilops species [33] or Wukong terminal repeat retrotransposons in miniature (TRIM) in maize germplasm [34]. In interspecific hybrids, especially in newly synthesized hybrids, the targets of structural reconstructions can be rDNA sequences [35], what was also found in our plant material. In these plants, the rearrangements between $F$. pratensis and $L$. perenne genomes in/or near rDNA position took place. Huang et al. [36] reported that fragile sites (FSs) in chromosomes of L. perenne are linked with $35 \mathrm{~S}$ rDNA cluster. The FSs are determined as regions that are prone to forming gaps or breaks on chromosomes. Human fragile sites are known as hotspots for chromosome aberrations, especially in many tumor cells $[37,38]$. However, in Festuca $\times$ Lolium plants, the analysis of the relation between FSs associated with $35 \mathrm{~S}$ rDNA regions and the location of structural rearrangements revealed that intergenomic changes did not correspond to FSs [39].

In theory, chromosomal rearrangements should not occur in allopolyploids due to preferential homologous chromosome pairing and sophisticated molecular processes preventing homoeologous recombination, such as Ph1 locus in wheat [40] or pairing regulators in Festuca-Lolium complex [41-44]. It is worth to highlight the differences between pairing control genes in both genera - in Festuca species genes are haplo-insufficient, while in Lolium genus this genetic system is effective both at the hetero- and homozygous stage [45]. Nevertheless, closely related plant species usually display the 

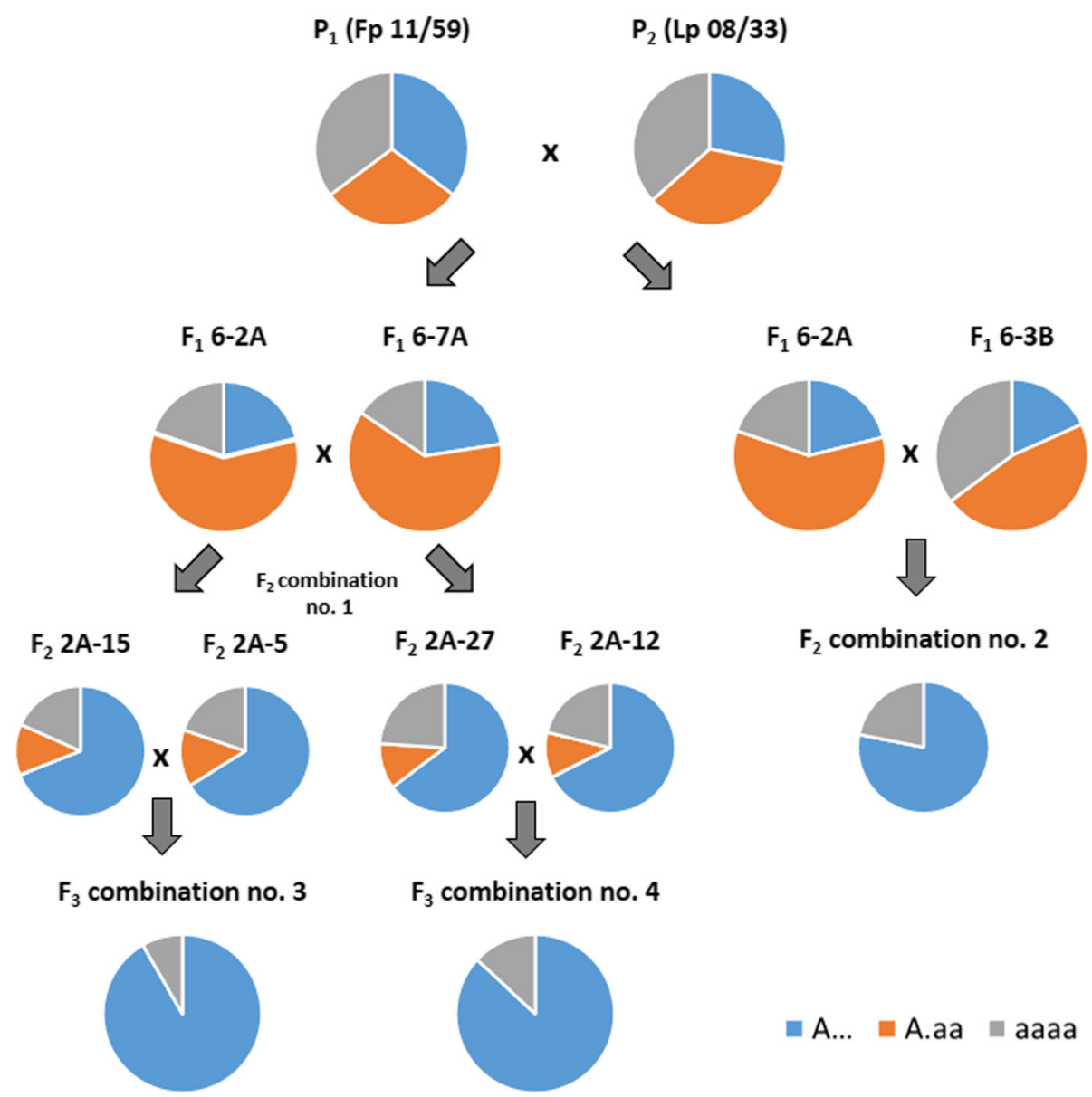

Fig. 5 The distribution of the most probable genotypes that was inferred based on the segregation of ISSR loci for parental genotypes, $F_{1}$ parents of both cross combinations and the $F_{2}$ parents of the cross combination no. 1. In case of ISSR loci segregation in $F_{2}$ generation from cross combination no. 2 and both $F_{3}$ generations, only the frequency of precedence (dominant) or absence (recessive, nulliplex) of ISSR band was taken into account

synteny of genomes and the collinearity of gene order, what can contribute to mispairing [46]. In the analyzed $\mathrm{F}_{2}-\mathrm{F}_{3}$ generations of $F$. pratensis $\times$ L. perenne, the recombinations between both genomes took place. Rearrangements that were recognized in $\mathrm{F}_{2}$ progeny are in contrary to the idea of Ramsey and Schemske [47]. According to their theory, homoeologous pairing is suspected to be avoided during meiosis in the $F_{1}$ generation following interspecific hybridization, because it can lead to infertility of progeny. Additionally, the increasing number of structural rearrangements in the next generations of $F$. pratensis $\times L$. perenne hybrid was observed, what is consistent with our previous findings [17, 48, 49]. Beyond the frequent and increasing occurrence of homoeologous rearrangements among $F_{2}-F_{3}$ plants, we identified also the examples of non-homologous recombination. This type of recombination between non-rDNA bearing chromosome of $F$. pratensis and region of chromosome 3L (chromosomal segment bearing 5S rDNA locus) took place (Fig. 3). Non-homologous chromosome pairing and recombination could be provoked by cross hybridization and rapid genome changes. It is thought that both types of recombination probably play a significant role in genome reshuffling and stabilization. Genomes of many polyploids, such as Triticum [50], Aegilops [51], Kengyilia species [52] or $\times$ Triticosecale [53] underwent genome reshufflings during the course of evolution (especially translocation, deletions and inversions). Chromosomal aberrations are mainly located in heterochromatic regions composed of repetitive DNA. The analysis of rearrangement distribution in $F$. pratensis $\times$ L. perenne amphiploid forms revealed terminal location as the most frequent (see Additional file 2: Table S1). The recombination rates along individual Festuca and Lolium chromosomes evaluated by Kopecký et al. [54] and King et al. [55] revealed that recombination sites are concentrated in intercalary regions of chromosome arms and reduced in their proximal and distal parts.

rDNA-FISH combined with GISH approach allowed us to unequivocally discriminate selected rDNA-bearing 
chromosome pairs in the complement of analyzed plant material. For these pairs of chromosomes, the analysis was more detailed and revealed, which pair was the most recombined. Knowledge about the types of rearrangements and their frequencies is essential to better understand the evolutionary significance of genome reshufflings [56]. In both studied generations, the high frequency of recombination was calculated for Festuca rDNA-bearing chromosomes, in $\mathrm{F}_{2}$ plants - for chromosome $2 \mathrm{~F}$, while in $\mathrm{F}_{3}$ plants - for chromosome $3 \mathrm{~F}$. The high value of rearrangements in chromosome $2 \mathrm{~F}$ was also depicted by Majka et al. [39] in $\mathrm{F}_{2}-\mathrm{F}_{9}$ generations of F. pratensis $\times$ L. perenne hybrid. Furthermore, the recognition of a particular chromosome pair revealed that in $\mathrm{F}_{3}$ prevailed plants with only one chromosome $2 \mathrm{~F}$. This odd number of the chromosome was inherited from parental forms - maternal plant had two chromosome 2F, while the pollinator did not have this pair of chromosomes. This unequivocal number of chromosomes $2 \mathrm{~F}$ was mainly related to a proper $(2 n=28)$ number of chromosomes. The loss of chromosome $2 \mathrm{~F}$ could be also associated with deletion of $35 \mathrm{~S}$ rDNA sequence or translocation of $35 \mathrm{~S}$ rDNA into another chromosome. Jumping of rDNA sequences, especially $35 \mathrm{~S}$ rDNA, is not the rare case in the plant kingdom [30, 33, 57].

The evolution of plant genomes, especially hybrids (including newly created by human and ancient natural hybrids) is related to genome and chromosome repatterning. In hybrid plants, the extensive interactions between genomes are observed. For hybrids derived from Festuca-Lolium complex (eight successive generations of $F$. pratensis $\times$ L. perenne hybrid), Zwierzykowski et al. [48, 49] observed preferential transmission of Lolium chromosomes, probably due to material selection for agronomic traits. However, the comparison of selected and unselected plants of $\mathrm{F}_{2}-\mathrm{F}_{4}$ generations of $F$. pratensis $\times$ L. perenne hybrid confirmed the dominance of Lolium over Festuca chromatin [58]. Our material was composed of plants without any selection and we also observed a higher number of Lolium chromosomes and drift in favor of Lolium in successive generations. Statistical analysis confirmed our hypothesis that asymmetrical variation between $F$. pratensis and $L$. perenne parental genomes exists. Nonetheless, Akiyama et al. [59] revealed no preferential transmission of the Lolium genome in consecutive generations of L. muliflorum $(2 \mathrm{x}) \times F$. arundinacea $(6 \mathrm{x})$ hybrids.

\section{The inheritance of ISSR loci}

During meiosis in autopolyploids, chromosomes may form multivalents leading to multisomic inheritance, where all the possible allelic combinations are formed in equal frequencies. In allopolyploids chromosomes usually pair with their homologs and form bivalents resulting in disomic inheritance. It has been observed, however, that both auto- and allopolyploids may shift between those two modes of inheritance and show intermediate or mixed inheritance [47], in which not all chromosomes have the same pairing behavior [6]. In addition, in the tetraploids two types of meiotic segregation may occur: random chromosome or random chromatid segregation, depending on the formation of bivalents or quadrivalents, respectively.

Our results suggest that in the $F_{1}$ hybrids most of ISSR loci segregated to gametes in a tetrasomic way, although the relatively small number of $F_{2}$ individuals did not allow us to determine which type of assortment: chromosome or chromatid might take place during meiosis of the $F_{1}$ hybrid. There was just one locus, which segregation suggested the possibility of quadrivalents formation and random chromatid segregation. Only in a few loci, disomic segregation could be accepted based on the $x^{2}$ test result. Their occurrence, however, proved the possibility of a mixed model of inheritance in Festulolium hybrid plants. From ISSR data only, it is not possible to decide whether there is any specific preference of chromosome pairing in particular chromosome homologue or homoeologue group. Nevertheless, from the nature of ISSR marker system, it may be assumed that the ISSR loci represent random positions in the genome and will be located in different chromosomes, suggesting that most of the chromosomes in $F_{1}$ hybrids may form intergenomic bivalents or multivalents during meiosis. As indicated by Zwierzykowski et al. [60] who studied the meiosis of $F$. pratensis $\times L$. perenne hybrids, the $F$. pratensis/L. perenne intergenomic bivalents were observed in about $33 \%$ of analyzed cells. A significant number of quadrivalents and some trivalents or univalent were also found. Such observations support the possibility of tetrasomic way of inheritance of ISSR loci, although, further analysis, for example with the use of ISSR amplification products as probes for in situ hybridization, may give more inside into this problem and shed more light on the chromosome vs. chromatid model of assortment of genetic material into the gametes.

An interesting observation was the occurrence of three ISSR loci, which seem to be inherited in different ways in both $F_{2}$ combinations. It may suggest that the choice between bivalent or multivalent pairing, at least for some chromosomes in the $F_{1}$ meiosis may be equally possible and take place at random.

Multivalent formation followed by a crossing-over located between the centromere and particular locus may in some cases lead to the migration of sister alleles to the same gamete during meiosis - a phenomenon known as a double reduction [61]. It may have a role in the purging of deleterious mutations through gametophytic 
selection [62], and could affect the distribution of gene frequency in polyploid populations [63]. In our study, a decline of ISSR polymorphism was found between subsequent generations. We understand that the dominant nature of ISSR markers does not allow to precisely measure the diversity, especially in tetraploid species, but it cannot be excluded that double reduction together with other mechanisms may be one of the reasons for this observation.

Our analysis of $\mathrm{F}_{3}$ plants shows that the mixed model of the inheritance probably persists in the subsequent generation, although this conclusion may only be speculative as almost all ISSR loci in $\mathrm{F}_{3}$ generation were not assigned to any specific model of inheritance. This high proportion of ISSR loci with an unknown type of inheritance, is another important factor to consider, as it may in some way bias our analysis. We cannot exclude, however, that irregular cytogenetic behaviors, such as the formation of univalents and trivalents, as evidenced in Zwierzykowski et al. [60] may contribute to the events with unknown inheritance mode. Here, further extending the sample size or the application of co-dominant markers and ISSR-FISH analysis may allow to specify the type of inheritance in $F$. pratensis $\times L$. perenne hybrids.

\section{Segregation distortion of ISSR loci}

Our ISSR analysis showed that only the minority of ISSR loci in $F_{2}$ and $F_{3}$ generations were characterized by segregation distortion (SD). They accounted for about 3.0\% and $15.0 \%$ in two $\mathrm{F}_{2}$ cross combinations and for $5.0 \%$ and $8.4 \%$ in the two $\mathrm{F}_{3}$ cross combinations. We are aware, however, that we might underestimate the frequency of this phenomenon, as the dominant type of ISSR markers does not allow to fully assign the genotypes at particular loci and, consequently, to test only these segregation ratios that are unambiguous. The possibility of underestimation of this result may be suggested by other studies of Festuca and/or Lolium hybrids. For example, the genetic mapping studies in $L$. perenne showed that depending on the mapping population used, the proportion of distorted loci ranged from $12 \%$ [64] to 60\% [65]. In the mapping study of $F$. arundinacea, segregation distortion was observed from $23 \%$ [66] to $45 \%$ of loci [67]. The mechanisms underlying SD are only partially understood and may involve various processes, such as differential inclusion of parental alleles into gametes (meiotic drive), differential fertilization success of specific gametes or differences in survival of haploid gametes or zygotes with specific allelic composition [68]. Some evidence suggests that SD is higher in interspecific than in intraspecific crosses [69, 70] thus being a reflection of more dynamic changes in the interspecific hybrids genomes.
The use of ISSR markers in our study suggest that there were no preferences in the transmission of either Festuca or Lolium ISSR alleles to the following generations of $F$. pratensis $\times L$. perenne hybrid, nor there were any preferences either for transmission of the dominant or recessive allele. Some preferences toward the transmission of the recessive allele were noticed in the $\mathrm{F}_{3}$ combination no. 4 , although it may be related to the relatively low number of loci under SD detected, and happened by a chance only. However, one concurrence may be noticed - more distorted loci were found in these populations, which parents were more polymorphic. Successful amplification of ISSR locus relies on two factors: $(i)$ the presence of two microsatellite sequences in the reverse complement orientation in DNA strand that are complementary to the oligonucleotide used for the PCR reaction, and (ii) the location of such sequences in a distance short enough to be amplified by routinely used polymerases and PCR assays. If the second mechanism will be considered, the lack of ISSR band will be a result of the too long distance between priming sites. This opens a possibility to think about the relationship between the length of Festuca and Lolium chromosomes and their possibility of successful pairing during meiosis. Distorted segregation may occur in these loci where an imbalance of a homoeologous chromosome segment length is present. Such hypothesis assumes that these chromosomes pair as multivalents and further suggests the intermediate or mixed model of inheritance in Festuca $\times$ Lolium hybrids.

\section{Conclusions}

The cytogenetic analysis of 134 plants of $F_{2}-F_{3}$ generations of $F$. pratensis $\times L$. perenne hybrid, including rDNA-FISH and GISH together with molecular genotyping of all plants by ISSR markers allowed us to draw conclusions from data reported herein. Cytogenetic genotyping of all analyzed hybrid plants revealed discrepancies in parental genomes (Festuca and Lolium) behavior. Statistical analysis of that data implies a genome drift over successive generations in allotetraploid $F$. pratensis $\times$ L. perenne hybrid. We observed the increasing number of Lolium chromosomes in the next generations of hybrids and significant differences between $F_{2}-F_{3}$ generations for recombined rDNA-bearing $L$. perenne chromosomes. Despite the decreasing total number of $F$. pratensis chromosomes, their chromosomes were more rearranged and statistical differences between analyzed generations for recombined rDNA-bearing and non-rDNA-bearing ones were recognized. Nevertheless, genotyping by ISSR markers analysis evidenced no preference in the transmission of either Festuca or Lolium alleles to the following generations of $F$. pratensis $\times L$. perenne hybrid. It is important, 
however, to bear in mind the different resolutions of both cytogenetic and molecular markers analysis. Furthermore, the analysis of ISSR loci inheritance in these hybrid plants revealed that the tetrasomic type of inheritance was characteristic for the majority of ISSR loci, but in some cases, the disomic type was also observed. This indicates that the mixed or intermediate model of alleles transmission may occur in the hybrids. Such possibility is in the agreement with the detection of non-homologous recombination events, as the multivalent formation may promote rearrangements between chromosomes from different genomes. Further examinations of the possible rearrangements combining chromosome and DNA level of resolution may give deeper insight into the nature of how the genome balance is achieved in F. pratensis $\times$ L. perenne hybrid.

\section{Methods}

\section{Plant material}

Allotetraploid $\mathrm{F}_{1}$ plants $(2 \mathrm{n}=4 \mathrm{x}=28)$ were produced by crossing the autotetraploid $(2 \mathrm{n}=4 \mathrm{x}=28)$ F. pratensis Huds. (cv. 'Westa'; Fp 11/59) (ㅇ) with the autotetraploid $(2 \mathrm{n}=4 \mathrm{x}=28)$ L. perenne L. (cv.'Solen'; Lp 08/33) (ठ). The $\mathrm{F}_{1}$ maternal plant $\left(\mathrm{F}_{1} 6-2 \mathrm{~A}\right)$ and two different $\mathrm{F}_{1}$ pollinators were used to produce two combinations of the $F_{2}$ generation: no. 1 - with $F_{1}$ pollinator 6-7A and no. 2 - with $F_{1}$ pollinator $6-3 B$. The $F_{3}$ generation (combinations no. 3 and 4) was obtained by crossing four randomly selected $\mathrm{F}_{2}$ plants derived from combination no. 1. The detailed scheme of crossing experiments was presented in Additional file 1: Fig. S1. All plant material derived from the collection of the Institute of Plant Genetics, Polish Academy of Sciences in Poznan, Poland.

\section{Preparation of root meristems}

Roots from plants growing in a greenhouse were excised and pretreated in ice-cold water for $24 \mathrm{~h}$, fixed in 3:1 (v/v) ethanol:glacial acetic acid and then stored at $-20{ }^{\circ} \mathrm{C}$ until required. Mitotic chromosome preparations were made using the excised roots, according to the procedure described in Majka et al. [71]. The high-quality slides were frozen and stored at $4{ }^{\circ} \mathrm{C}$ until used.

\section{Fluorescent in situ hybridization}

The FISH procedure was carried out according to the protocol published in Majka et al. [71]. The hybridization mixture consisted of $50 \%$ deionized formamide, $10 \%$ dextran sulfate, $2 \times \mathrm{SSC}, 0.5 \%$ SDS, $10 \mu \mathrm{g}$ salmon sperm blocking DNA and 100-120 ng/slide both rDNA probes. In FISH experiments the following probes were used: $(i)$ the 5S rDNA sequence, generated from the wheat clone pTa794 [72] and (ii) 35S rDNA sequence, generated from a 2.3-kb ClaI sub-clone of the $25 \mathrm{~S}$ rDNA coding region of
Arabidopsis thaliana [73]. 5S rDNA was labeled by PCR technique with universal M13 primers by using tetramethyl-rhodamine-5-dUTP (Roche, Mannheim, Germany), while 35S rDNA probe was prepared by nick translation with digoxigenin-11-dUTP (Roche, Mannheim, Germany). Chromosome preparations were denatured at $80^{\circ} \mathrm{C}$ for $2 \mathrm{~min}$ in presence of hybridization mixture and hybridized overnight in a humid chamber at $37^{\circ} \mathrm{C}$. Post-hybridization washes in $0.1 \times \mathrm{SSC}$ at $42^{\circ} \mathrm{C}$ provided an equivalent of $79 \%$ stringency. Digoxigenin-labeled probes were detected by fluorescein isothiocyanate-conjugated (FITC) anti-digoxigenin antibody (Roche, Mannheim, Germany). Chromosomes were counterstained with $2.5 \mathrm{mg} / \mathrm{ml} \mathrm{4',6-diamidino-2-phenylindole} \mathrm{(DAPI,} \mathrm{Sigma,}$ St. Louis, Missouri) in antifade Vectashield solution (Vector Laboratories, Burlingame, CA, USA).

The chromosome nomenclature used for rDNA-bearing chromosomes was developed by Thomas et al. [74] According to this, there are two rDNA-bearing chromosomes in $F$. pratensis karyotype: chromosomes $2 \mathrm{~F}$ (bearing 35S rDNA loci) and 3F (bearing $5 \mathrm{~S}$ rDNA). Whereas in the $L$. perenne karyotype, chromosomes 3L (bearing $5 \mathrm{~S}$ and $35 \mathrm{~S}$ rDNA in opposite arms) and a group of chromosomes 1, 2 and $7 \mathrm{~L}$ (bearing $35 \mathrm{~S}$ rDNA) can be recognized.

\section{Genomic in situ hybridization}

For the GISH experiments all the chromosome spreads, which had been used in FISH, were applied. Therefore, before GISH, the sets of probes from previous experiments were rinsed off. The GISH procedure was carried out according to the protocol of Majka et al. [39]. Genomic DNA of $L$. perenne, which was mechanically sheared to fragments of $5-10 \mathrm{~kb}$ by boiling for $30-45 \mathrm{~min}$ and labeled by nick translation with digoxigenin-11-dUTP (Roche, Mannheim, Germany), was used as a probe in GISH experiments. While the nuclear DNA of $F$. pratensis was used as a blocking DNA (sheared to the shorter fragments by boiling for 10-15 min). The probe was detected using a FITC conjugated anti-digoxigenin antibody. The chromosome preparations were counterstained in Vectashield (Vector Laboratories, Burlingame, CA, USA) containing $1.5 \mathrm{~g} / \mathrm{ml}^{-1}$ of propidium iodide.

\section{Image capturing and data processing}

Images were captured using an Olympus XM10 CCD camera attached to an Olympus BX 61 automatic epifluorescence microscope. Final image adjustments were done with Olympus Cell-F imaging software (ver. 3.1; Olympus Soft Imaging Solutions GmbH, Germany) and Micrographx Picture Publisher software (ver. 10; Corel Corporation, Canada).

Cytogenetic data were statistically processed by the $\chi^{2}$ test and t-test within GenStat ${ }^{\bullet}$ (ver. 16; VSN Int.). Analysis 
was performed to compare the distributions of selected cytogenetic traits within and between $\mathrm{F}_{2}$ and $\mathrm{F}_{3}$ generations, as well as to evaluate the difference between both parental genomes in $\mathrm{F}_{2}-\mathrm{F}_{3}$ generations of $F$. pratensis $\times L$. perenne hybrid. The comparison between $\mathrm{F}_{2}$ and $\mathrm{F}_{3}$ generations was performed for the $F_{2}$ cross combination no. 1 only, because of crossing scheme - combinations no. 3 and $4\left(\mathrm{~F}_{3}\right.$ generation) were obtained by crossing plants that derived from combination no. 1 of $\mathrm{F}_{2}$ generation.

\section{DNA isolation and ISSR-PCR analysis}

DNA samples were extracted from young leaves using CTAB method [75]. ISSR-PCRs were carried out in a volume of $25 \mu$ l containing $70 \mathrm{ng}$ of genomic DNA, $2 \times$ PCR buffer, $2.5 \mathrm{mM} \mathrm{MgCl}, 2.5 \mathrm{mM}$ dNTP, $10 \mathrm{mM}$ of each primer and 0.25 units of Taq DNA Polymerase (Thermo Scientific, Waltham, Massachusetts). The thermal profile for ISSR-PCR was as follows: $94^{\circ} \mathrm{C}$ for $2 \mathrm{~min}$ - initial denaturation, then 35 cycles of $95^{\circ} \mathrm{C}$ for $30 \mathrm{~s}$, the temperature of annealing was depended on primer $\left(48-57^{\circ} \mathrm{C}\right)$ for $1 \mathrm{~min}$ and elongation at $72^{\circ} \mathrm{C}$ for $1 \mathrm{~min}$. A final extension step $-5 \mathrm{~min}$ at $72^{\circ} \mathrm{C}$. The temperature of annealing and sequences of analyzed oligonucleotides were shown in Additional file 10: Table S9. ISSR amplification products were separated in 2.0\% agarose gels (EURx, Gdańsk, Poland), stained with ethidium bromide (Sigma, St. Louis, Missouri) and visualized under UV light and photographed (Syngen UV visualizer). GeneRuler Ladder (Novazym, Poznań, Poland) was used to determine the size of the DNA fragments.

\section{The analysis of ISSR loci polymorphism}

In order to estimate the level of polymorphism between parental plants: F. pratensis (Fp 11/59) and L. perenne (Lp 08/33) and between pairs of the $F_{1}$ and $F_{2}$ individuals used as parents for subsequent generations, all the bands produced by each ISSR primer were counted. The entire set of bands was composed of monomorphic products present in both analyzed forms and polymorphic products characteristic for individual genotypes. The level of polymorphism was defined as the percentage of polymorphic bands for all the primer combinations (see Additional file 11: Table S10 and Additional file 12: Table S11). The Polymorphism Information Content (PIC) was calculated using iMEC program [76].

\section{The analysis of ISSR loci segregation}

Based on the presence or absence of ISSR band, the possible genotypes were assigned to parental $F$. pratensis and $L$. perenne plants and to the $F_{1}$ and $F_{2}$ genotypes which were used as parents for subsequent cross combinations. As both parental plants (Fp 11/59 and Lp 08/ 33) are autotetraploids, we assumed that their chromosomes will segregate to gametes in a tetrasomic way and we have taken into account the possibility of random chromosome or random chromatic segregation. The individuals of $F_{1}$ and $F_{2}$ generation were allotetraploids, but our observations suggest that both tetrasomic and disomic inheritance of chromosomes is possible, although it was found that bivalent formation is more frequent in the hybrid [77]. Taking into account this observation as well as the dominant type of ISSR markers that were used in our study and the relatively low sample size, which does not allow to distinguish between chromosome vs. chromatid assortment, we made most of the later calculations based on the simplified assumption of the random chromosome segregation model. This allowed us to divide the types of inheritance into tetrasomic and disomic, based on the different possible rates of band segregation, depending on the genotypes in each ISSR locus in parental individuals (see Additional file 13: Table S12). All possible segregation ratios for random chromosome segregation model were tested using the $x^{2}$ test. We assumed that the lack of segregation distortion is more probable than its occurrence. In all cases, where only one segregation ratio passed the $X^{2}$ test $(P<0.05)$, the one was selected as describing the most probable inheritance type in particular ISSR locus. When more segregation rates passed the $x^{2}$ tests and some of them were characteristic to different inheritance types, we assumed such result as ambiguous with unknown inheritance type. When none of the segregation rates passed the $X^{2}$ test, such locus was treated as segregation distortion and a possible signature of genomic changes between parental plants and the subsequent $F_{2}$ and/or $F_{3}$ generations. To confirm the probability of segregation distortion of such locus it was additionally analyzed for those segregation ratios that are characteristic for random chromatid segregation model, which assumes quadrivalent formation (see Additional file 13: Table S12).

\section{Additional files}

Additional file 1: Figure S1. The scheme of crossing experiments. (TIF $1581 \mathrm{~kb}$ )

Additional file 2: Table S1. Cytogenetic genotyping in F. pratensis, L. perenne, $F$. pratensis $\times L$. perenne hybrids $\left(F_{1}\right)$ and in the following $F_{2}-F_{3}$ generations. (XLSX $85 \mathrm{~kb}$ )

Additional file 3: Table S2. The Polymorphism Information Content (PIC) calculated for individual ISSR primer and the PIC mean value. PIC values are provided for individuals that were used as parents for each of the cross combinations, as well as for the $F_{2}$ and $F_{3}$ populations. (XLSX $11 \mathrm{~kb})$

Additional file 4: Table S3. The results of $X^{2}$ test of ISSR bands segregation in combination no. 1 of $F_{2}$ generation of $F$. pratensis $X L$. perenne hybrid. (XLSX $38 \mathrm{~kb}$ )

Additional file 5: Table S4. The results of $X^{2}$ test of ISSR bands segregation in combination no. 2 of $F_{2}$ generation of $F$. pratensis $\times L$. perenne hybrid. (XLSX $39 \mathrm{~kb})$ 
Additional file 6: Table S5. List of the most probable genotypes of $\mathrm{P}_{1}$ $\mathrm{P}_{2}$ and $\mathrm{F}_{1}$ parental plants for each of SSR locus. (XLSX $17 \mathrm{~kb}$ )

Additional file 7: Table S6. The results of $X^{2}$ test of ISSR bands segregation in combination no. 3 of $F_{3}$ generation of $F$. pratensis $\times L$. perenne hybrid. (XLSX $45 \mathrm{~kb}$ )

Additional file 8: Table S7. The results of $X^{2}$ test of ISSR bands segregation in combination no. 4 of $F_{3}$ generation of $F$. pratensis $\times L$. perenne hybrid. (XLSX $47 \mathrm{~kb}$ )

Additional file 9: Table S8. List of the most probable genotypes of $P_{1}$, $P_{2}, F_{1}$, and $F_{2}$ parental plants for each of ISSR locus. (XLSX $18 \mathrm{~kb}$ )

Additional file 10: Table S9. Specification of analyzed oligonucleotides. (XLSX $10 \mathrm{~kb}$ )

Additional file 11: Table S10. ISSR band pattern in combinations no. 1 and 2 of $F_{2}$ generation of $F$. pratensis $\times L$. perenne hybrid. (XLSX $40 \mathrm{~kb}$ )

Additional file 12: Table S11. ISSR band pattern in combinations no. 3 and 4 of $F_{3}$ generation of $F$. pratensis $\times L$. perenne hybrid. (XLSX $30 \mathrm{~kb}$ )

Additional file 13: Table S12. Possible segregation ratios for the disomic and tetrasomic inheritance of ISSR loci depending on the possible genotypes and band pattern in parental species $-F$. pratensis and $L$. perenne and in the $F_{2}-F_{3}$ generations of $F$. pratensis $\times L$. perenne hybrid. For simplicity, the $F_{1}$ genotypes were described using one letter code (A or a), regardless of the origin of particular allele from Festuca or Lolium parent. (XLSX $10 \mathrm{~kb}$ )

\section{Abbreviations}

DAPI: 4'6-diamidino-2-phenylindole; FISH: Fluorescent in situ hybridization; FSs: Fragile Sites; GISH: Genomic in situ hybridization; ISSR: Inter-Simple Sequence Repeats; PIC: Polymorphism Information Content; SD: Segregation Distortion

\section{Acknowledgments}

We thank Professor Arkadiusz Kosmala (Institute of Plant Genetics, Polish Academy of Sciences, Poznań, Poland) for valuable comments on the manuscript.

\section{Funding}

JM acknowledges scholarship from the National Science Center (Poland); Etiuda project (no. 2018/28/T/NZ9/00074).

\section{Availability of data and materials}

All data generated and analyzed during this study are included in this published article (and its supplementary information files).

\section{Authors' contributions \\ $J M$ and TK conceived and designed the experiments. JM performed the experiments. JM, KB, AJ, PK, HCK and TK analyzed the data. JM, KB and AJ drafted the manuscript. JM, PK and ZZ revised the paper. All authors read and approved the final manuscript.}

\section{Ethics approval and consent to participate}

Not applicable.

\section{Consent for publication}

Not applicable.

\section{Competing interests}

The authors declare that have no competing interests.

\section{Publisher's Note}

Springer Nature remains neutral with regard to jurisdictional claims in published maps and institutional affiliations.

\section{Author details}

'Department of Environmental Stress Biology, Institute of Plant Genetics, Polish Academy of Sciences, Poznań, Poland. '2Department of Botany and Nature Protection, University of Silesia in Katowice, Katowice, Poland.

${ }^{3}$ Department of Genetics, University of Silesia in Katowice, Katowice, Poland. ${ }^{4}$ Department of Biometry and Bioinformatics, Institute of Plant Genetics,

Polish Academy of Sciences, Poznań, Poland.

Received: 25 October 2018 Accepted: 3 May 2019

Published online: 14 May 2019

\section{References}

1. Leitch AR, Leitch IJ. Genomic plasticity and the diversity of polyploid plants. Science. 2008;320(5875):481-3. https://doi.org/10.1126/science.1153585.

2. Murat F, Xu JH, Tannier E, Abrouk M, Guilhot N, Pont C, et al. Ancestral grass karyotype reconstruction unravels new mechanisms of genome shuffling as a source of plant evolution. Genome Res. 2010;20:1545-57. https://doi.org/ 10.1101/gr.109744.110

3. Salse J. Deciphering the evolutionary interplay between subgenomes following polyploidy: a paleogenomics approach in grasses. Am J Bot. 2016; 103(7):1167-74. https://doi.org/10.3732/ajb.1500459.

4. Wendel JF. Genome evolution in polyploids. Plant Mol Biol. 2000:42:225-49.

5. Catalan P, Gabriel SMJ, Palop-Esteban M, Moreno C, Gonzalez-Candelas F. A Bayesian approach for discriminating among alternative inheritance hypotheses in plant polyploids: the allotetraploid origin of genus Borderea (Dioscoreaceae). Genetics. 2006;172:1939-53. https://doi.org/10.1534/ genetics.105.042788

6. Jeridi M, Perrier X, Rodier-Goud M, Ferchichi A, D'Hont A, Bakry F. Cytogenetic evidence of mixed disomic and polysomic inheritance in an allotetraploid (AABB) Musa genotype. Ann Bot. 2012;110(8):1593-606. https://doi.org/10.1093/aob/mcs220.

7. Reflinur KB, Jang SM, Chu S. Analysis of segregation distortion and its relationship to hybrid barriers in rice. Rice. 2014;7:3. https://doi.org/10.1186/ s12284-014-0003-8.

8. Thomas HM, Thomas BJ. Meiosis of triploid Lolium. I. Synaptonemal complex formation and chromosome configurations at metaphase I in aneuploid autotriploid L. multiflorum. Genome. 1994;37:181-9.

9. Zwierzykowski Z, Tayyar R, Brunell M, Lukaszewski AJ. Genome recombination in intergeneric hybrids between tetraploid Festuca pratensis and Lolium multiflorum. J Hered. 1998;89(4):324-8.

10. Zhang H, Bian Y, Gou X, Zhu B, Xu C, et al. Persistent whole-chromosome aneuploidy is generally associated with nascent allohexaploid wheat. Proc Natl Acad Sci U S A. 2013;110:3447-52. https://doi.org/10.1073/pnas. 1300153110.

11. Kopecký D, Bartos J, Lukaszewski AJ, Baird JH, Černoch V, Kölliker R, et al. Development and mapping of DArT markers within the Festuca-Lolium complex. BMC Genomics. 2009;10:473. https://doi.org/10.1186/1471-2164-10-473.

12. Jang TS, Emadzade K, Parker J, Temsch EM, Leitch AR, Speta F, WeissSchneeweiss H. Chromosomal diversification and karyotype evolution of diploids in the cytologically diverse genus Prospero (Hyacinthaceae). BMC Evol Biol. 2013;13:136. https://doi.org/10.1186/1471-2148-13-136.

13. Thomas HM, Morgan WG, Meredith MR, Humphreys MW, Thomas $H_{\text {, }}$ Leggett JM. Identification of parental and recombined chromosomes in hybrid derivatives of Lolium multiflorum x Festuca pratensis by genomic in situ hybridization. Theor Appl Genet. 1994;88:909-13.

14. King IP, Morgan WG, Armstead IP, Harper JA, Hayward MD, Bollard A, et al. Introgression mapping in the grasses I. introgression of Festuca pratensis chromosomes and chromosome segments into Lolium perenne. Heredity. 1998;81:462-7.

15. Kopecký D, Loureiro J, Zwierzykowski Z, Ghesquière M, Doležel J. Genome constitution and evolution in Lolium $\times$ Festuca hybrid cultivars (Festulolium). Theor Appl Genet. 2006;113:731-42. https://doi.org/10.1007/s00122-0060341-z.

16. Kosmala A, Zwierzykowski Z, Gasior D, Rapacz M, Zwierzykowska E, Humphreys MW. GISH/FISH mapping of genes for freezing tolerance transferred from Festuca pratensis to Lolium multiflorum. Heredity. 2006;96:243-51.

17. Książczyk T, Zwierzykowska E, Molik K, Taciak M, Krajewski P, Zwierzykowski Z. Genome-dependent chromosome dynamics in three successive generations of the allotetraploid Festuca pratensis $\times$ Lolium perenne hybrid. Protoplasma. 2015;252:985-96. https://doi.org/10.1007/s00709-014-0734-9. 
18. Thomas $\mathrm{H}$, Humphreys MO. Progress and potential of inter-specific hybrids of Lolium and Festuca. Agric Sci. 1991;117:1-8.

19. Humphreys MW, Zare AG, Panakinskiene I, Thomas H, Rogers WJ, Collin HA. Interspecific genomic rearrangements in androgenic plants derived from a Lolium multiforum $\times$ Festuca arundinacea $(2 n=5 x=35)$ hybrid. Heredity. 1998;80:78-82. https://doi.org/10.1007/s00122-006-0341-z.

20. Udall JA, Quijada PA, Osborn TC. Detection of chromosomal rearrangements derived from homeologous recombination in four mapping populations of Brassica napus L. Genetics. 2005;169:967-79. https://doi.org/ 10.1534/genetics.104.033209

21. Madlung A, Tyagi AP, Watson B, Jiang HM, Kagochi T, Doerge RW, et al. Genomic changes in synthetic Arabidopsis polyploids. Plant J. 2005;41:221-30. https://doi.org/10.1111/j.1365-313X.2004.02297.x

22. Vitte C, Panaud O. LTR retrotransposons and flowering plant genome size: emergence of the increase/decrease model. Cytogen Genom Res. 2005;110:91-107.

23. Vitte C, Peterson T, Bennetzen JL. Transposable elements and the evolving structure of the maize genome, in: Advances in maize. In: Prioul $J \mathrm{~L}$, Thevenot C, Molnar T, editors. the Society for Experimental Biology, London, UK: Taylor \& Francis, vol. 3, 2-36. p. 2011.

24. Lim KY, Kovarik A, Matyasek R, Bezdeek M, Lichtenstein CP, Leitch AR. Gene conversion of ribosomal DNA in Nicotiana tabacum is associated with undermethylated, decondensed and probably active gene units. Chromosoma. 2000;109:161-72

25. Pontes O, Neves N, Silva M, Lewis MS, Madlung A, Comai L, et al. Chromosomal locus rearrangements are a rapid response to formation of the allotetraploid Arabidopsis suecica genome. Proc Natl Acad Sci U S A. 2004;101:18240-5. https://doi.org/10.1073/pnas.0407258102.

26. Ozkan H, Levy AA, Feldman M. Allopolyploidy-induced rapid genome evolution in the wheat (Aegilops-Triticum) group. Plant Cell. 2001;13:1735-47.

27. Shaked H, Kashkush K, Ozkan H, Feldman M, Levy AA. Sequence elimination and cytosine methylation are rapid and reproducible responses of the genome to wide hybridization and allopolyploidy in wheat. Plant Cell. 2001; 13:1749-59. https://doi.org/10.1105/TPC.010083.

28. Renny-Byfield S, Kovarík A, Chester M, Nichols RA, Macas J, Novák P, Leitch AR. Independent, rapid and targeted loss of highly repetitive DNA in natural and synthetic allopolyploids of Nicotiana tabacum. PLoS One. 2012:e36963. https://doi.org/10.1371/journal.pone.0036963.

29. Linares C, Gonzalez J, Ferrer E, Fominaya A. The use of double fluorescence in situ hybridization to physically map the positions of $5 \mathrm{~S}$ rDNA genes in relation to the chromosomal location of $18 \mathrm{~S}-5.8 \mathrm{~S}-26 \mathrm{~S}$ rDNA and a $\mathrm{C}$ genome specific DNA sequence in the genus Avena. Genome. 1996:39:535-42.

30. Lan T, Albert VA. Dynamic distribution patterns of ribosomal DNA and chromosomal evolution in Paphiopedilum, a lady's slipper orchid. BMC Plant Biol. 2011;11:126. https://doi.org/10.1186/1471-2229-11-126.

31. Pedrosa-Harand A, Souza de Almeida CC, Mosiolek M, Blair MW, Schweizer D, Guerra M. Extensive ribosomal DNA amplification during Andean common bean (Phaseolus vulgaris L.) evolution. Theor Appl Genet. 2006;112:924-33. https://doi.org/10.1007/s00122-005-0196-8.

32. Zhang J, Yu C, Krishnaswamy L, Peterson T. Transposable elements as catalysts for chromosome rearrangements. Methods Mol Biol. 2010;701:315-26. https:/doi.org/10.1007/978-1-61737-957-4_18.

33. Raskina O, Belyayev A, Nevo E. Quantum speciation in Aegilops: molecular cytogenetic evidence from rDNA cluster variability in natural populations. Proc Natl Acad Sci U S A. 2004;101:14818-23. https://doi.org/10.1073/pnas. 0405817101.

34. Liu Z, Li X, Messing J, Xu JH. The Wukong terminal-repeat Retrotransposon in miniature (TRIM) elements in diverse maize Germplasm. G3. 2015:5:158592. https://doi.org/10.1534/g3.115.018317.

35. Volkov RA, Komarova NY, Hemleben V. Ribosomal DNA in plant hybrids: inheritance, rearrangement, expression. Syst Biodivers. 2007;5(3):261-76. https://doi.org/10.1017/S1477200007002447

36. Huang J, Ma L, Yang F, S-z F, Li L. 45S rDNA regions are chromosome fragile sites expressed as gaps in vitro on metaphase chromosomes of root-tip meristematic cells in Lolium spp. PLoS One. 2008;3:e2167. https://doi.org/10. 1371/journal.pone.0002167.

37. Debatisse $M$, Le Tallec B, Letessier A, Dutrillaux B, Brison O. Common fragile sites: mechanisms of instability revisited. Trends Genet. 2012;28(1):22-32.

38. Glover TW. Fragile sites in cancer: more than meets the eye. Nat Rev Cancer. 2017;17(8):489-501.
39. Majka J, Zwierzykowski Z, Majka M, Kosmala A. Karyotype reshufflings of Festuca pratensis $\times$ Lolium perenne hybrids. Protoplasma. 2018;255:451-8. https://doi.org/10.1007/s00709-017-1161-5.

40. Riley R, Chapman V. Genetic control of cytologically diploid behaviour of hexaploid wheat. Nature. 1958;182:713-5.

41. Jauhar PP. Genetic control of diploid-like meiosis in hexaploid tall fescue. Nature. 1975;254:595-7.

42. Jauhar PP. Genetic regulation of diploid-like chromosome pairing in the hexaploid species, Festuca arundinacea Schreb. And F. rubra L. (Gramineae). Chromosoma. 1975;52:363-82.

43. Evans GM, Davies EW. The genetics of meiotic chromosome pairing in Lolium temulentum $\times$ Lolium perenne tetraploids. Theor Appl Genet. 1985;71:185-92.

44. Armstead IP, Bollard A, King IP, Forster JW, Hayward MD, Evans GM, Thomas $\mathrm{HM}$. Chromosome pairing in Lolium perenne $\times$ L. temulentum diploid hybrids: genetic and cytogenetic evaluation. Heredity. 1999:83:298-303.

45. Jenczewski $E$, Alix K. From diploids to allopolyploids: the emergence of efficient pairing control genes in plants. Crticial Rev Plant Sci. 2004;23(1):21-45.

46. Taylor SJ, Rojas LD, Ho SW, Martin NH. Genomic collinearity and the genetic architecture of floral differences between the homoploid hybrid species Iris nelsonii and one of its progenitors, Iris hexagona. Heredity. 2013;110:63-70. https://doi.org/10.1038/hdy.2012.62.

47. Ramsey J, Schemske DW. Neopolyploidy in flowering plants. Annu Rev Ecol Syst. 2002;33:589-639. https://doi.org/10.1146/annurev.ecolsys.33.010802. 150437.

48. Zwierzykowski Z, Kosmala A, Zwierzykowska E, Jones N, Jokś W, Bocianowski J. Genome balance in six successive generations of the allotetraploid Festuca pratensis × Lolium perenne. Theor Appl Genet. 2006;113:539-47. https://doi.org/10.1007/s00122-006-0322-2.

49. Zwierzykowski Z, Zwierzykowska E, Taciak M, Kosmala A, Jones RN, Zwierzykowski W, et al. Genomic structure and fertility in advanced breeding populations derived from an allotetraploid Festuca pratensis $\times$ Lolium perenne cross. Plant Breed. 2011;130:476-80. https://doi.org/10.1111/j. 1439-0523.2010.01839.x.

50. Ma J, Stiller J, Berkman PJ, Wei Y, Rogers J, Feuillet C, et al. Sequence-based analysis of translocations and inversions in bread wheat (Triticum aestivum L.). PLoS One. 2013;8(11):e79329. https://doi.org/10.1371/journal.pone. 0079329.

51. Badaeva ED, Amosova AV, Samatadze TE, Zoshchuk SA, Shostak NG, Chikida NN, et al. Genome differentation in Aegilops. 4. Evolution of the U-genome cluster. Plant Syst Evol. 2004;246:45-76.

52. Wang Q, Liu H, Gao A, Yang X, Liu W, Li X, Li L. Intergenomic rearrangements after polyploidization of Kengyilia thoroldiana (Poaceae: Triticeae) affected by environmental factors. PLoS One. 2012;7:e31033. https://doi.org/10.1371/journal.pone.0031033.

53. Bento M, Pereira HS, Rocheta M, Gustafson P, Viegas W, Silva M. Polyploidization as a retraction force in plant genome evolution: sequence rearrangements in triticale. PLoS One. 2008;3(1):e1402. https://doi.org/10. 1371/journal.pone.0001402.

54. Kopecký D, Havránková M, Loureiro J, Castro S, Lukaszewski AJ, Bartoš J, et al. Physical distribution of homoeologous recombination in individual chromosomes of Festuca pratensis in Lolium multiflorum. Cytogen Gen Res. 2010:129:162-72.

55. King J, Armstead I, Harper J, Ramsey L, Snape J, Waugh R, et al. Exploitation of interspecific diversity for monocot crop improvement. Heredity. 2013;110:475-83.

56. Badaeva ED, Dedkova OS, Gay G, Pukhalskyi VA, Zelenin AV, Bernard S, Bernard M. Chromosomal rearrangements in wheat: their types and distribution. Genome. 2007:50:907-26.

57. Schubert I, Wobus U. In situ hybridization confirms jumping nucleolus organizing regions in Allium. Chromosoma. 1985;92:143-8.

58. Zwierzykowski Z, Książczyk T, Taciak M, Zwierzykowska E, Jones N, Kosmala A. Genome constitution in selected and unselected plants of $F_{2}-F_{4}$ generations derived from an allotetraploid Festuca pratensis $\times$ Lolium perenne hybrid. In: Barth S, Milbourne D, editors. Breeding Strategies for Sustainable Forage and Turf Grass Improvement: Springer Science+Business Media, Dodrecht; 2012. p. 75-9. https://doi.org/10.1007/978-94-007-4555-1_9.

59. Akiyama Y, Ueyama Y, Hamada S, Kubota A, Kato D, Yamada-Akiyama H, et al. Utilization of flow cytometry for Festulolium breeding (Lolium multiflorum $(2 x) \times$ Festuca arundinacea (6x)). Breed Sci. 2016;66:234-43. https://doi.org/ $10.1270 /$ jsbbs.66.234 
60. Zwierzykowski Z, Zwierzykowska E, Taciak M, Jones N, Kosmala A, Krajewski P. Chromosome pairing in allotetraploid hybrids of Festuca pratensis $X$ Lolium perenne revealed by genomic in situ hybridization (GISH). Chromosom Res. 2008;16(4):575-85.

61. Gupta PK. Cytogenetics: An Advanced Study. Meerut New Delhi: Rastogi Publications; 2015

62. Butruille DV, Boiteux LS. Selection-mutation balance in polysomic tetraploids: impact of double reduction and gametophytic selection on the frequency and subchromosomal localization of deleterious mutations. Proc Natl Acad Sci U S A. 2000;97:6608-13.

63. Wright S. The distribution of gene frequencies in populations of polyploids. Proc Natl Acad Sci U S A. 1938;24:372-7.

64. Bert PF, Charmet G, Sourdille P, Hayward MD, Balfourier F. A high-density molecular map for ryegrass (Lolium perenne) using AFLP markers. Theor Appl Genet. 1999:99:445-52. https://doi.org/10.1007/s001220051256.

65. Jensen LB, Andersen JR, Frei U, Xing Y, Taylor C, Holm PB, Lübberstedt T. QTL mapping of vernalisation response in perennial ryegrass (Lolium perenne L.) reveals co-location with an orthologue of wheat VRN1. Theor Appl Genet. 2005;110:527-36. https://doi.org/10.1007/s00122-004-1865-8

66. Saha MC, Mian R, Zwonitzer JC, Chekhovskiy K, Hopkins AA. An SSR- and AFLP-based genetic linkage map of tall fescue (Festuca arundinacea Schreb.). Theor Appl Genet. 2005;110:323-36. https://doi.org/10.1007/s00122-004-1843-1.

67. Dierking R, Azhaguvel P, Kallenbach R, Saha M, Bouton J, Chekhovskiy K, et al. Linkage maps of a mediterranean $\times$ continental tall fescue population and their comparative analysis with other Poaceae species. Plant Genome. 2015, 2015;8. https://doi.org/10.3835/plantgenome2014.07.0032.

68. Fishman L, Willis $\mathrm{JH}$. A novel meiotic drive locus almost completely distorts segregation in mimulus (monkeyflower) hybrids. Genetics. 2005;169(1):347-53. https://doi.org/10.1534/genetics.104.032789.

69. Causse MA, Fulton TM, Cho YG, Ahn SN, Chunwongse J, Wu K, et al. Saturated molecular map of the rice genome based on an interspecific backcross population. Genetics. 1994;138(4):1251-74.

70. Jenczewski E, Gherardi M, Bonnin I, Prosperi JM, Olivieri I, Huguet T. Insight on segregation distortions in two intraspecific crosses between annual species of Medicago (Leguminosae). Theor Appl Genet. 1997;94:682-91.

71. Majka J, Książczyk T, Kiełbowicz-Matuk A, Kopecký D, Kosmala A. Exploiting repetitive sequences and BAC clones in Festuca pratensis karyotyping. PLoS One. 2017;12(6):e0179043. https://doi.org/10.1371/journal.pone.0179043.

72. Gerlach WL, Dyer TA. Sequence organisation of the repeating units in the nucleus of wheat which contain 5S rRNA genes. Nucl Acids Res. 1980;8:4851-65.

73. Unfried I, Gruendler P. Nucleotide sequence of the 5.85 and $25 S$ rRNA genes and the internal transcribed spacers from Arabidopsis thaliana. Nucl Acids Res. 1990;1:4011.

74. Thomas HM, Harper JA, Meredith MR, Morgan WG, King IP. Physical mapping of ribosomal DNA sites in Festuca arundinacea and related species by in situ hybridization. Genome. 1997;40:406-10.

75. Doyle JJ, Doyle JL. A rapid total DNA preparation procedure for fresh plant tissue. Focus. 1990;12:13-5.

76. Amiryousefi A, Hyvönen J, Poczai P. iMEC: online marker efficiency calculator. Appl Plant Sci. 2018;6:e01159.

77. Canter PH, Pasakinskiene I, Jones RN, Humphreys MW. Chromosome substitutions and recombination in the amphiploid Lolium perenne $x$ Festuca pratensis cv prior ( $2 \mathrm{n}=4 \mathrm{x}=28)$. Theor Appl Genet. 1999;98:809-14

Ready to submit your research? Choose BMC and benefit from:

- fast, convenient online submission

- thorough peer review by experienced researchers in your field

- rapid publication on acceptance

- support for research data, including large and complex data types

- gold Open Access which fosters wider collaboration and increased citations

- maximum visibility for your research: over $100 \mathrm{M}$ website views per year

At $\mathrm{BMC}$, research is always in progress.

Learn more biomedcentral.com/submissions 